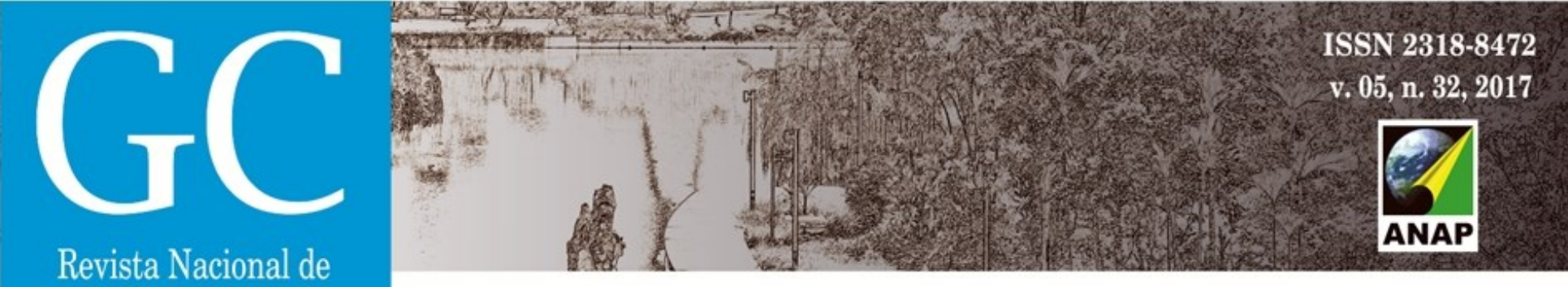

\title{
Cidades e Rios no Oeste Paulista - Rio Tietê e a cidade de Barra Bonita
}

Cities and Rivers in the Oeste Paulista - Rio Tietê and the city of Barra Bonita

Ciudades y Ríos en el Oeste Paulista - Rio Tietê y la ciudad de Barra Bonita

Viviane Gasparini Mota

Discente da FAAC/UNESP

vi.gasparinimota@gmail.com

Norma Regina Truppel Constantino

Docente da FAAC/UNESP

nconst@faac.unesp.br 


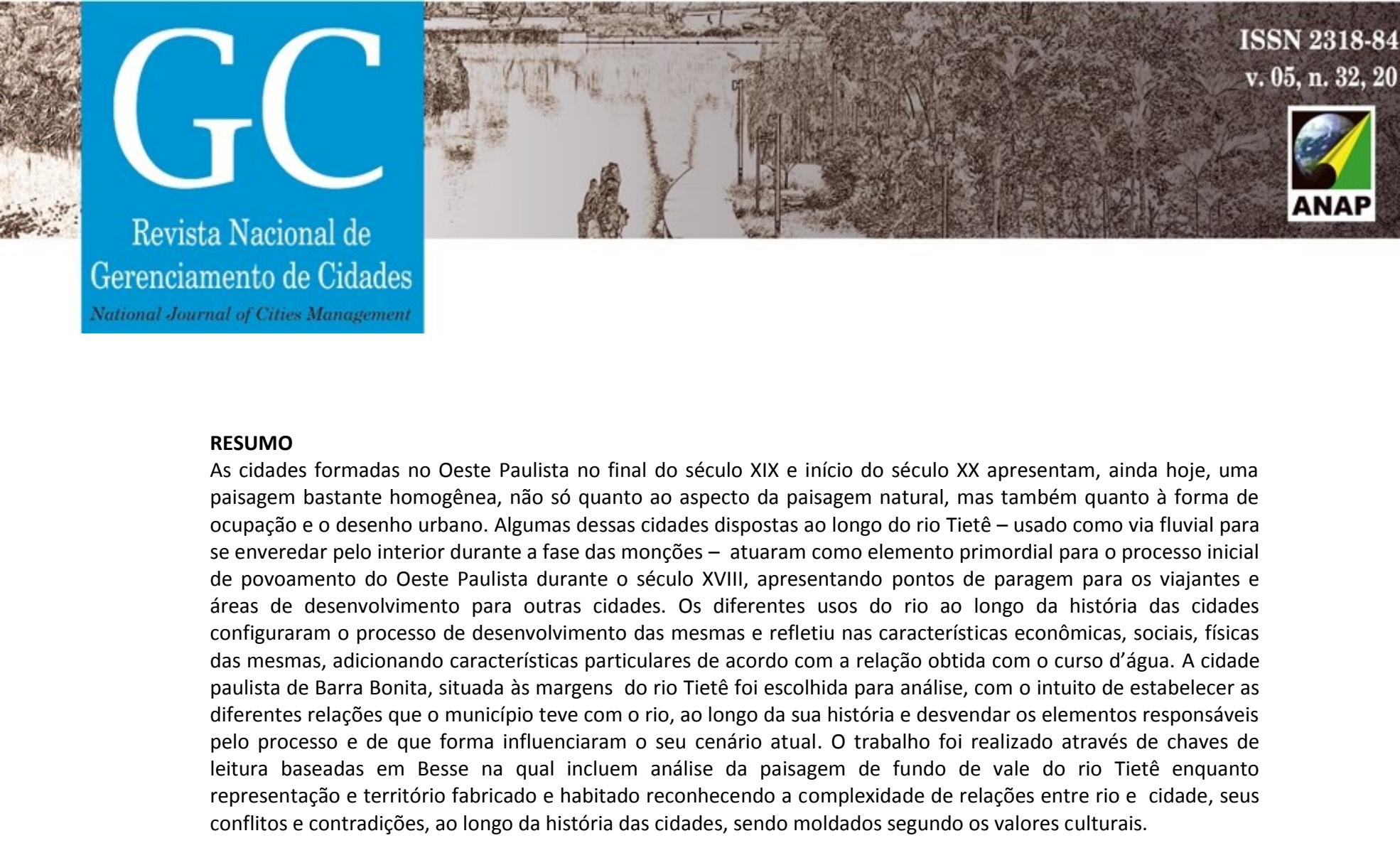

\section{RESUMO} ocupação e o desenho urbano. Algumas dessas cidades dispostas ao longo do rio Tietê - usado como via fluvial para se enveredar pelo interior durante a fase das monções - atuaram como elemento primordial para o processo inicial de povoamento do Oeste Paulista durante o século XVIII, apresentando pontos de paragem para os viajantes e paulista de Barra Bonita, situad às margens do rio Tietê foi escolhida para análise, com o intuito de estabelecer as diferentes relações que o município teve com o rio, ao longo da sua história e desvendar os elementos responsáveis pelo processo e de que forma influenciaram o seu cenário atual. 0 trabalho foi realizado através de chaves de representação e território fabricado e habitado reconhecendo a complexidade de relações entre rio e cidade, seus conflitos e contradições, ao longo da história das cidades, sendo moldados segundo os valores culturais.

PALAVRAS-CHAVE: Barra Bonita. Rios Urbanos. Oeste Paulista.

\section{RESÚMEN}

Las ciudades formadas en el oeste paulista al final de siglo XIX y en el inicio del siglo XX presentan, incluido hoy en día, un paisaje homogéneo, no solamente en su aspecto natural, pero también en cuanto a su forma de ocupación y diseño urbano. Algunas de estas ciudades dispuestas a lo largo del rio Tietê -- usado como vía fluvial para trasladarse por el interior durante la fase de monzones - actuaran como elemento primordial para el proceso inicial de asentamiento poblacional del Oeste Paulista durante el siglo XVIII, presentando puntos de parada para los viajeros e áreas de desenvolvimiento para otras ciudades. Los diferentes usos del rio a lo largo de la historia de las ciudades configurarían el proceso de desenvolvimiento de las mismas y se reflejarían en las características económicas, sociales y físicas de las mismas, adicionando características particulares de acuerdo con la relación obtenida con el uso del curso del agua. La ciudad paulista de Barra Bonita, ubicada en los márgenes del rio Tietê fue escogida para análisis, con la intención de establecer las diferentes relaciones que el municipio tuvo con el rio, a lo largo de su historia y revelar los elementos responsables por el proceso y de qué forma estos influenciaran el escenario actual. El trabajo fue realizado a través de llaves de lectura en Besse el cual incluye analicé del paisaje del fondo de valle del rio Tietê como representación e territorio fabricado e habitado reconociendo la complexidad de relación entre rio e ciudad, sus conflictos e contradicciones, a lo largo de la historia de las ciudades, siendo moldados según sus valores culturales

\section{ABSTRACT}

The cities formed on western Sao Paulo near the end of the $19^{\text {th }}$ century and the beginning of the $20^{\text {th }}$ show a homogenous landscape, not only in their natural landscape but also within their occupation and urban design. Some of the cities along the Tietê river - used as a waterway to dislocate in the center of the state of Sao Paulo during the monsoon station - - will act as a primordial element for the initial settlement of western Sao Paulo during the $18^{\text {th }}$ century, presenting stopping spots for travelers and developed zones for other cities. The different use of the river along the citieshistorieswill set up their development process and will reflect in their economics, social, and physical characteristics, in some cases adding particular characteristics in correlation with their use with the water course. The city of Barra Bonita (State of Sao Paulo), located near the margins of the Tietêriver was chosen to be analyzed, with the intention ofestablishing the different relations that the county had with the river, throughout its history and unveil the elements responsible for the process and in what waythey will shape the current scenery. The work was done with reading keys based on Besse, in which it is included landscape analysis of Tietê's valley bottom as a representation andfabricated territory and inhabited recognizing the complexity of relations between city and river. Its conflicts and complications throughout the cities histories, being shaped in correlation of their cultural values. 


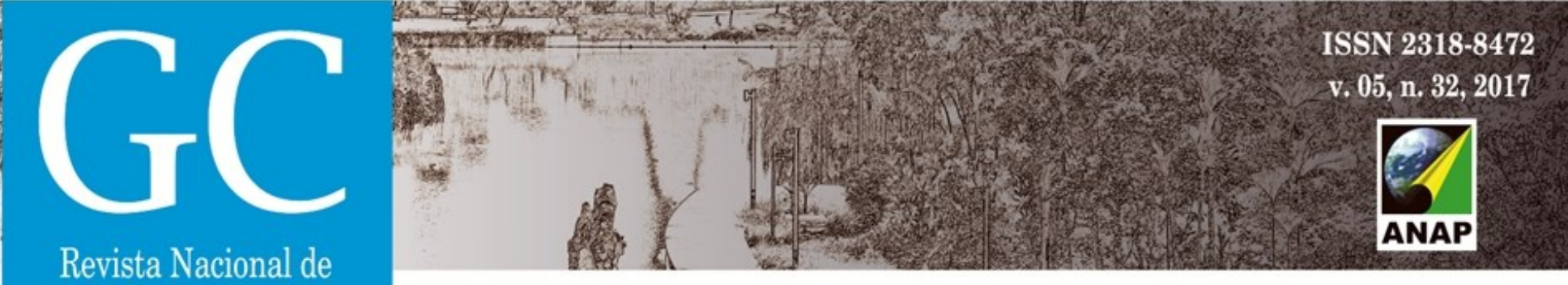

Gerenciamento de Cidades

\section{INTRODUÇãO}

Compreender que a paisagem é uma construção social está vinculado com duas questões de extrema importância. A primeira desenvolve o conceito de paisagem admitindo sua dimensão temporal, ou seja, sua transformação contínua através de dinâmicas, sejam dos ciclos naturais de criação ou destruição ou de mudanças culturais sobre o espaço. Essas alterações podem surgir em diversas escalas e amplitudes, mas é isto a maior qualidade a respeito deste conceito. A segunda questão é de que toda paisagem é cultural, portanto construída, seja tanto nas suas formas quanto nas percepções. Logo, é uma representação mental, verbal, gravada sobre uma tela ou reproduzida em um território. Para cada situação, o território é movido por características paisagísticas distintas, próprias do interesse de quem o analisa.

"Os traços, as impressões da atividade humana, mais genericamente da vida, que passa sobre o solo, deixa suas marcas"

(Besse, 2006, p.67)

O processo de implantação dos primeiros povoados no Brasil iniciou-se próximas aos rios justificadas pelas necessidades básicas de permanência num espaço. Entretanto, as cidades implantadas ao longo de rios de importância histórica como o Tiete e o Rio Paraná - usados como via fluvial para se enveredar pelo interior durante a fase das monções - apresentam-se como elemento primordial para o processo inicial de povoamento do Oeste Paulista durante o século XVIII, atuando como pontos de paragem para os viajantes e áreas de desenvolvimento para outras cidades. Os diferentes usos do rio ao longo da história das cidades configuraram o processo de desenvolvimento das mesmas e refletiu nas características econômicas, sociais, físicas das mesmas, adicionando características particulares de acordo com a relação obtida com o curso d'água.

\section{OBJETIVOS}

A pesquisa tem por objetivo analisar a relação entre o Rio Tietê e o município de Barra Bonita, através do levantamento histórico associado com os principais acontecimentos modeladores da paisagem acontecidos ao rio na região do Oeste Paulista, descrevendo como se processa nos dias atuais a relação de interferência entre as variáveis rio e cidade, sendo pautada nos seguintes aspectos: a questão das permanências, a forma de ocupação, a sua inserção nos Planos Diretores Participativos e outras legislações municipais e as relações existentes entre os habitantes da cidade e o rio Tietê. Desta maneira, o intuito é estabelecer as diferentes relações 


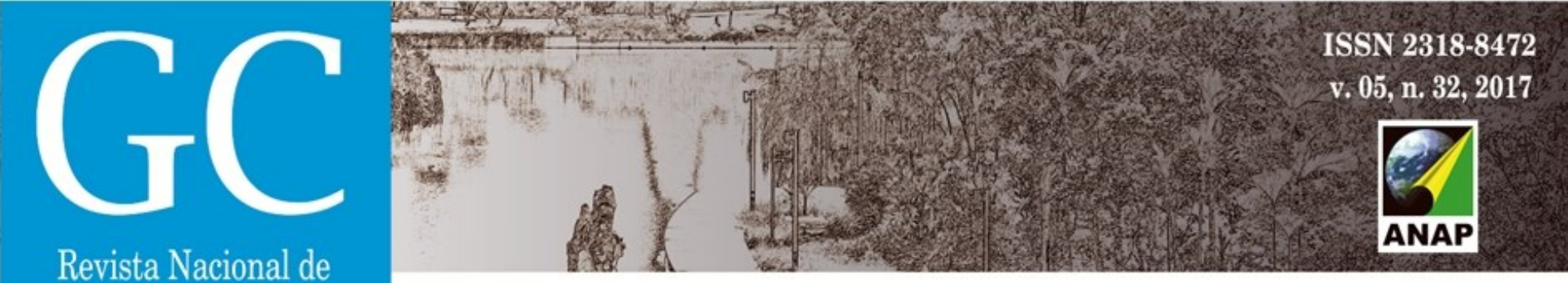

Gerenciamento de Cidades

que as cidades tiveram com o rio, ao longo da sua história e desvendar os elementos responsáveis pelo processo e de que forma influenciaram o cenário atual dos municípios.

\section{METODOLOGIA}

O recorte geográfico escolhido para o desenvolvimento da pesquisa é a cidade paulista de Barra Bonita, São levados em consideração os vínculos entre paisagem e patrimônio cultural, através de chaves de leitura baseadas em Besse na qual incluem análise da paisagem de fundo de vale do rio Tietê enquanto representação e território fabricado e habitado reconhecendo a complexidade de relações entre os rios e as cidades, seus conflitos e contradições, ao longo da história das cidades, sendo moldados segundo os valores culturais. O estudo sera feito através de mapas, fotos aéreas, fotografias e pinturas, disponível em museus, bibliotecas e prefeituras municipais. Além disso, é feita a análise da paisagem urbana e sua relação com o Rio Tietê, verificando a existência de projetos urbanísticos e paisagísticos envolvendo as áreas ribeirinhas.

\section{RESULTADOS}

A formação da cidade está intimamente relacionada com as águas do Tietê, desde as primeiras tentativas de ocupação até sua estruturação econômica. Historicamente, Barra Bonita é dividida em 4 fases, de acordo com sua relação com o Rio Tietê.

O homem relaciona-se com o rio desde seus primórdios. Local de fácil obtenção de água potável, seu uso abrangeu diversas atividades, primariamente básicas como banho, obtenção e cozimento de alimentos, saciedade da sede e posteriormente mais complexas como via de transporte, abastecimento e irrigação. No processo de transformação da paisagem natural para paisagem urbana, percebemos a importância da água na implantação das primeiras povoadas brasileiros, onde o rio traçava a localização das cidades à medida que era desbravado cresciam para o interior do país. Durante o período colonial, os rios paulistanos passaram a ser utilizados pelas monções - expedições e frotas comerciais - que transportavam alimentos às minas de Goiás e ao Mato Grosso e exploravam o sertão desconhecido. 0 aparecimento das cidades brasileiras não invalidou sua importância, pelo contrário, o rio tornou-se local estratégico para a implantação dos primeiros povoados ${ }^{1}$ (LANGENBUCH, 1971 e CORRÊA \& ALVIM, 2000). Portanto, a primeira fase é marcada pelas primeiras tentativas de povoamento da região determinadas pela criação do primeiro porto na área de várzea do rio.

As monções - expedições fluviais com papel importante na colonização brasileira, comuns no início do século 18 utilizavam dos períodos de cheias dos rios para navegar rumo a Goiás e Minas Gerais em busca de ouro (ciclo do ouro Brasil). Estas partiam do porto paulista de Araritaguaba, atual Porto Feliz, no Vale do Médio Tiete. Da mesma forma que as histórias míticas têm sua origem incerta, a origem da parada e do porto para o sertão na cidade de 



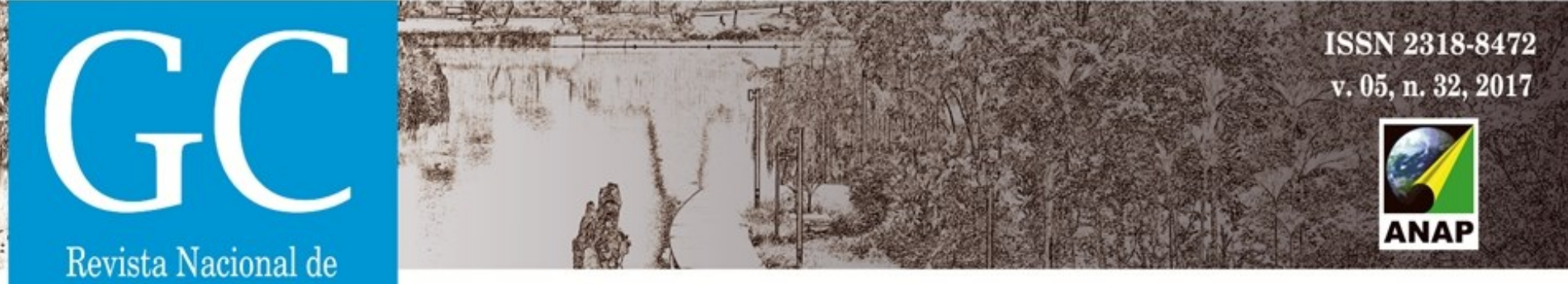

boiadas e um pequeno entreposto foi construído entre dois córregos ao lado do rio Tietê,denominado de "Casa Azul". Tropeiros, boiadeiros e fazendeiros realizavam a paragem na casa azul antes de seguir $18 \mathrm{~km}$ em direção à Estação de Banharão, localidade da futura cidade de Jaú. As primeiras edificações de pau a pique foram levantadas, sendo até sugerido a fundação de um povoado ali. Entretanto outro agrupamento de casas surgiu, precedido pela instalação do "Porto Barra Bonita" pela Navegação Fluvial Ytuana, dessa vez, mais próximo do rio. A análise das causas do segundo agrupamento de moradores ter prosperado em detrimento do primeiro, indica a importância do primeiro porto como fundamental para o estabelecimento de comunicação e comércio da região. Às margens do rio, junto à foz do córrego, o porto de Barra Bonita florescia, marcado pela construção de um barracão de madeira que atendia às necessidade de embarque e desembarque de café e outras mercadorias. Casebres foram sendo construídos próximo ao porto para atender aos viajantes que chegavam tanto nos comboios de carroça ou pelos vapores. O mapa a seguir (Figura 2) mostra a localização dos dois povoados na área da cidade de Barra Bonita. A "Casa Azul" localizava-se entre dois córregos, onde atualmente encontra-se a fazenda da família Dalla Vale, e o "Porto Barra Bonita" localizava-se próximo à foz do córrego Barra Bonita. A distância entre os agrupamentos é de aproximadamente 7,9 km em linha reta.

Figura 2: Tentativas de Povoamento

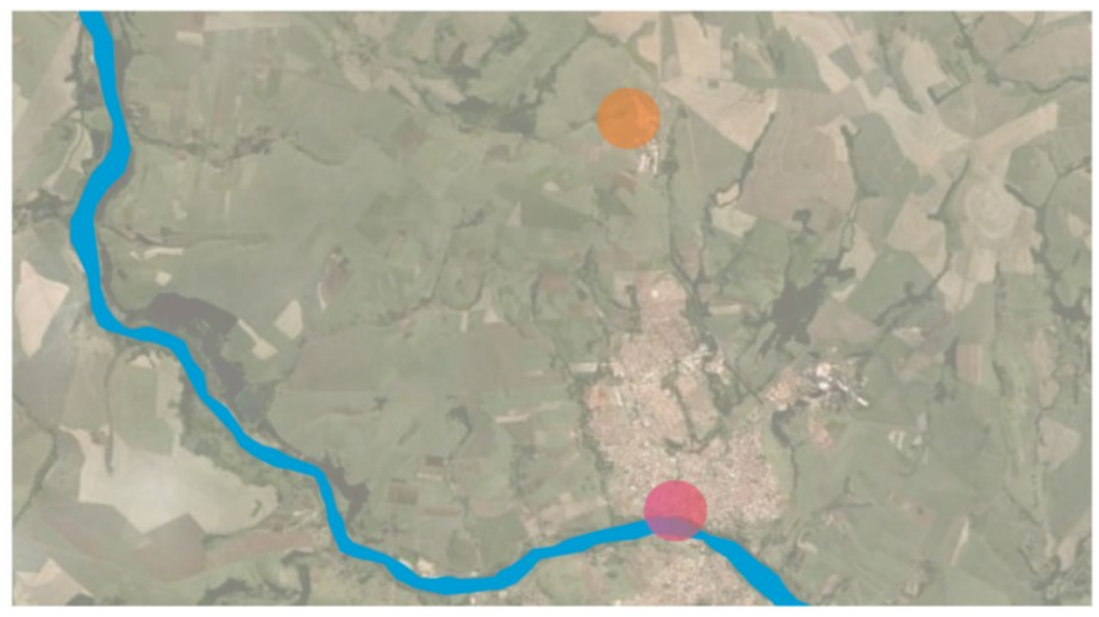

\section{Rio Tietê}

\section{$1^{\circ}$ Tentativa de povoamento}

$2^{\circ}$ Tentativa de povoamento

Fonte: Intervenção da autora na área sobre mapa do GoogleMaps.

O Coronel José de Salles Leme, fazendeiro de café que possuía grandes propriedades na região, viu no desenvolvimento do porto uma oportunidade de estabelecer ali um ponto 


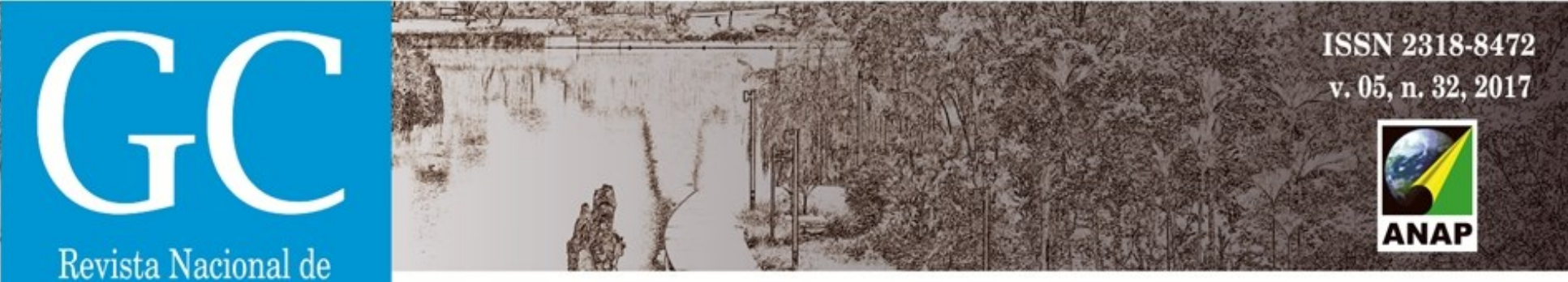

Gerenciamento de Cidades

comercial. Em sociedade com João Baptista Pompeu, a Sociedade Mercantil Salles \& Pompeu foi erguida atendendo moradores do pequeno povoado com alimentos, tecidos e ferragens. Além disso, era ponto de encontro com autoridades e fazendeiros viajantes.

Não somente importante para o desenvolvimento comercial, a edificação apresenta suma importância na formação do desenho urbano de Barra Bonita. Distante a 50 metros da margem do córrego Barra Bonita e a 300 metros do rio Tietê (Rua 1o de Março, esquina com a rua Salvador de Toledo), a casa comercial estabeleceu o ponto de fundação do povoado oficializado em 19 de março de 1883 - e o futuro centro comercial (Figura 3). A eficiência da localização permitiu a proximidade com o porto, respeitando uma distância mínimacom as margens e suas enchentes, e possibilitando a contigüidade ao córrego pela fácil obtenção de água potável. As construções posteriores, mantiveram a mesma racionalidade da casa comercial, em relação ao seu entorno ( SAFFI, et al., 1999).

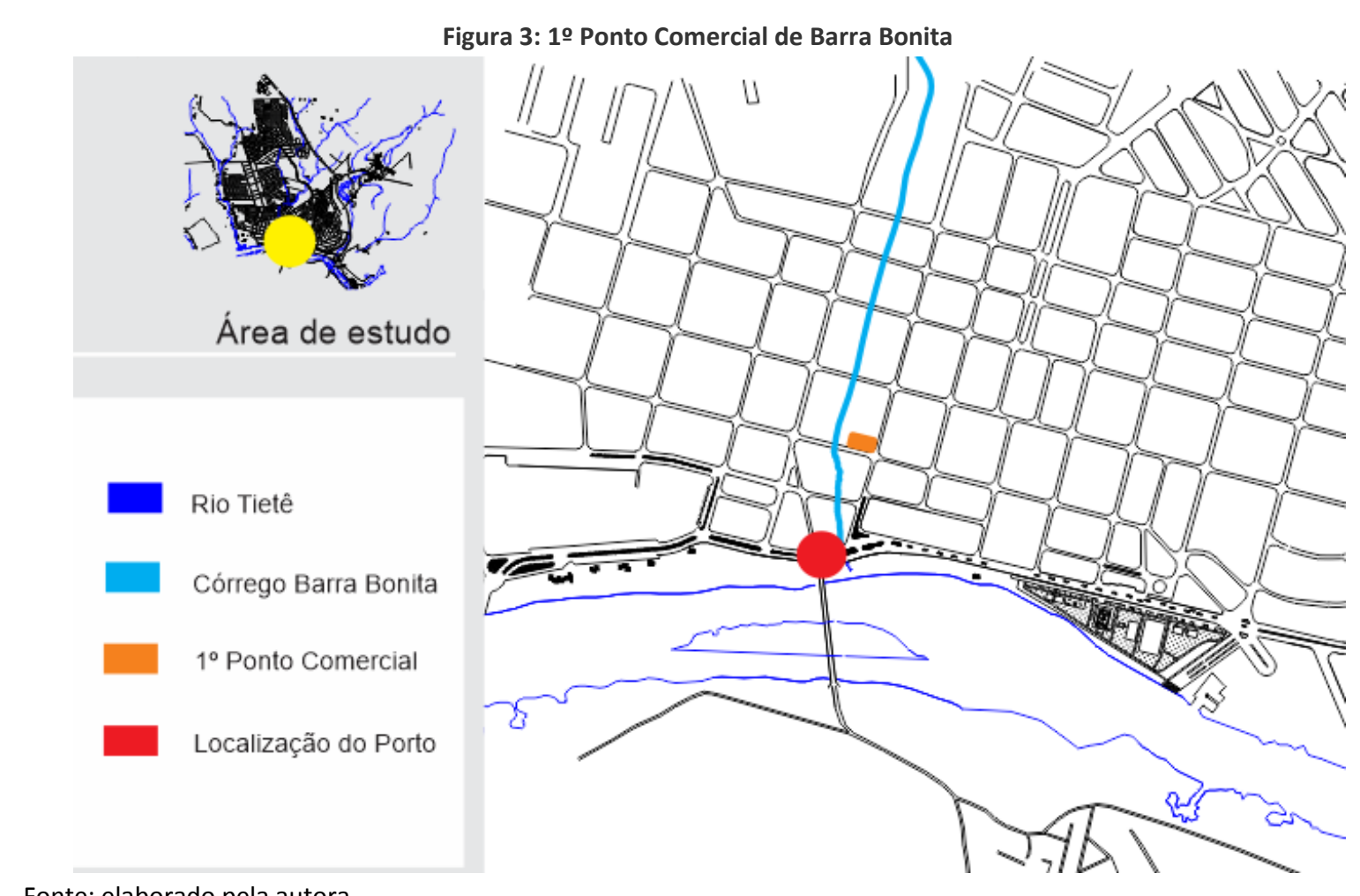

Fonte: elaborado pela autora

A segunda fase, caracterizada pelo crescimento no setor cafeeiro associado ao fortalecimento das atividades portuárias, é responsável pela explosão populacional e oficialização de Barra Bonita como cidade. O Estado de São Paulo recebeu grande leva de imigrantes no final do 


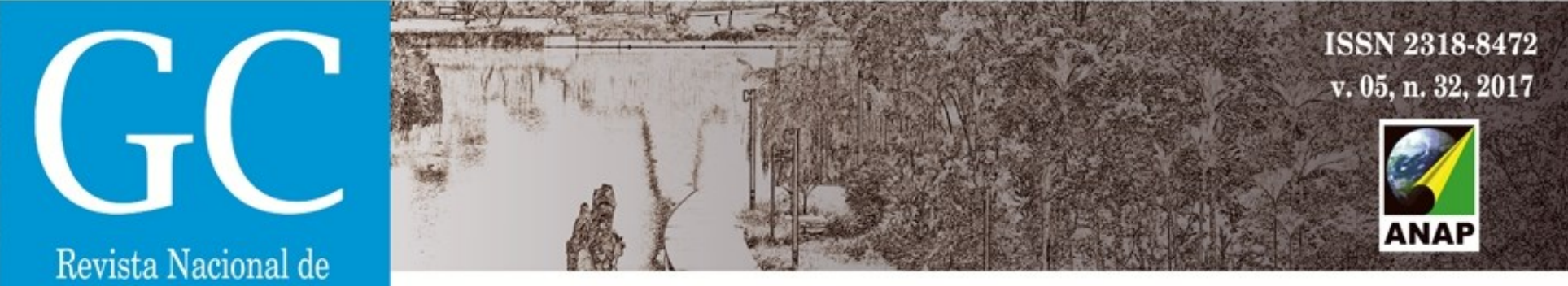

Gerenciamento de Cidades

National Journal of Cities Management

século 19, a partir da adoção do trabalho livre nas fazendas cafeeiras, incentivando a proliferação de núcleos populacionais no interior e o aumento significativo populacional nos povoados e cidades pré-existentes. Antes da Lei Áurea, tinha-se uma média inferior a 6 mil imigrantes chegando anualmente no porto de Santos. Com o acréscimo de investimentos pelo governo brasileiro para fomentar a imigração frente à Implantação da Lei Áurea em 13 de Maio de 1888, aproximadamente 885 mil imigrantes chegam no período entre 1887 e 1900 (SILVA, 2013).

A partir da década de 1880, Barra Bonita e região passaram a receber expressivas quantidades de imigrantes, entre eles espanhóis, sírios, alemães e principalmente italianos. Do porto de Santos, eram encaminhados para diversas localidades do estado de São Paulo, para trabalharem principalmente em atividades rurais. $O$ café atua como protagonista no processo de urbanização das cidades do interior, a medida que recebe a mão de obra livre e abre caminho para atividades secundárias e crescimento da indústria. Entretanto, só foi possível o crescimento cafeeiro na região, pelo estabelecimento do Porto de Barra Bonita pela Navegação Fluvial Ytuana (atuante desde 1875), que efetuava o transporte das sacas de café que eram distribuídas através do uso dos vapores no rio Tietê (Figura 4), processo rápido e eficaz visto que a ferrovia só viria posteriormente. A medida que o setor agrícola se expandia, novas instalações foram providenciadas no porto para armazenar grandes quantidades de produtos.

Figura 4: O vapor "Visconde de Itú", a lancha e os armazéns da "Sorocabana"

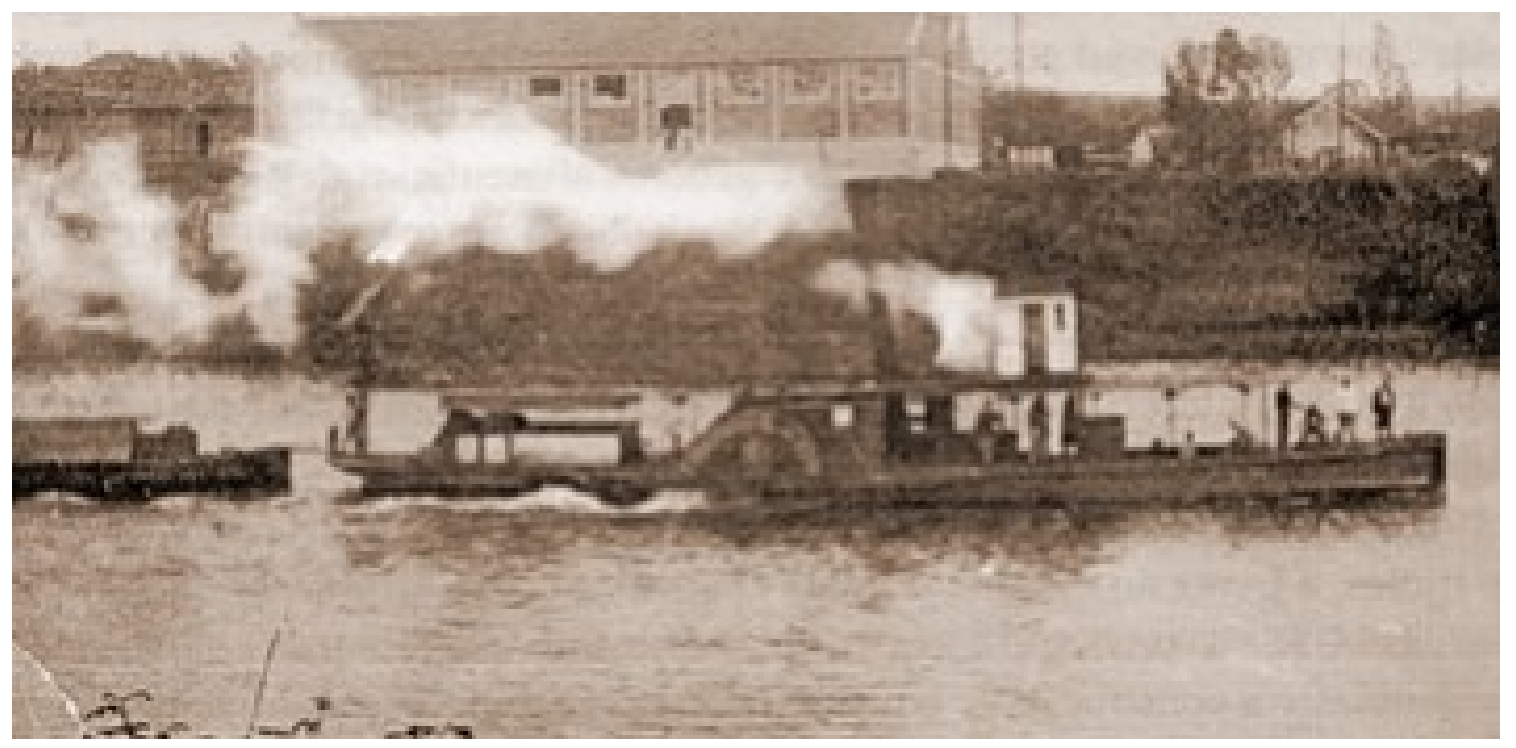

Fonte: SAFFI et al., 1999. Disponível em:https://barrabonita.sp.gov.br/?page=livro-100-anos-de-historia 


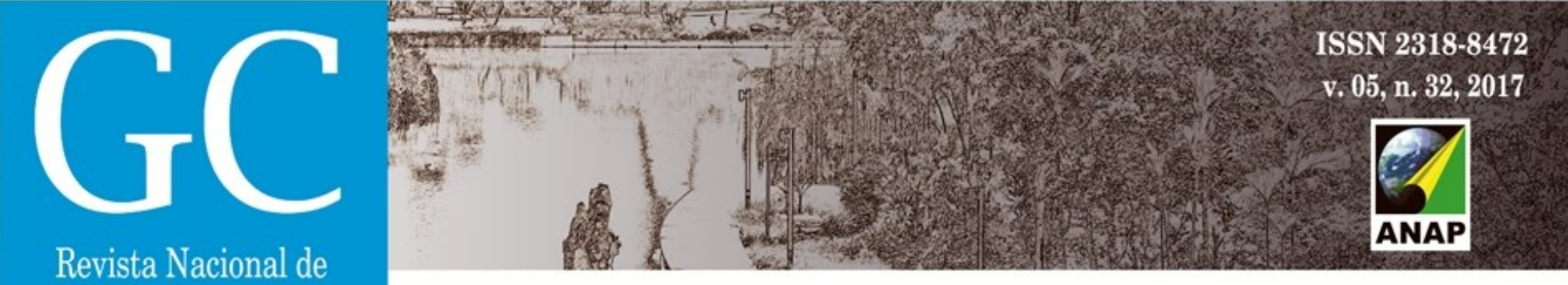

Gerenciamento de Cidades

A influência do imigrante para a formação de Barra Bonita teve também papel fundamental na decisão da construção da primeira capela da cidade. José de Salles Leme cedeu o terreno de uma de suas propriedades para a primeira capela em louvor a São José - Padroeiro da Cidade, em 30 de Setembro de 1889. Com o rápido progresso, Barra Bonita é elevada a município em 1912 (Lei no 1338 de 14 de Novembro de 1912), garantindo o impulso final para seu desenvolvimento. Como cidade, um dos primeiros atos oficiais aprovados foi a nomeação e desenho das principais ruas em 15 de abril de 1913. A lógica seguia o entorno da rua 10 de Março - primeira via pública aberta na cidade e que durante muitos anos foi considerada a data de fundação da mesma - pois ali, anos antes iniciaram-se as atividades comerciais. As primeiras ruas implantadas no sentido norte-sul foram: Tiradentes, Winifrida, Primeiro de Março, Campos Salles, Salles Leme, Coronel Virgilio e Rio Branco. Suas transversais eram: Marechal Floriano, Quatorze de Dezembro, Prudente de Moraes, Salvador de Toledo, Major Pompeu e Otero. A seguir, a forma urbana da cidade em 1913, sobreposta sobre a malha atual:

Figura 5: Sistema Viário da cidade de Barra Bonita em 1913

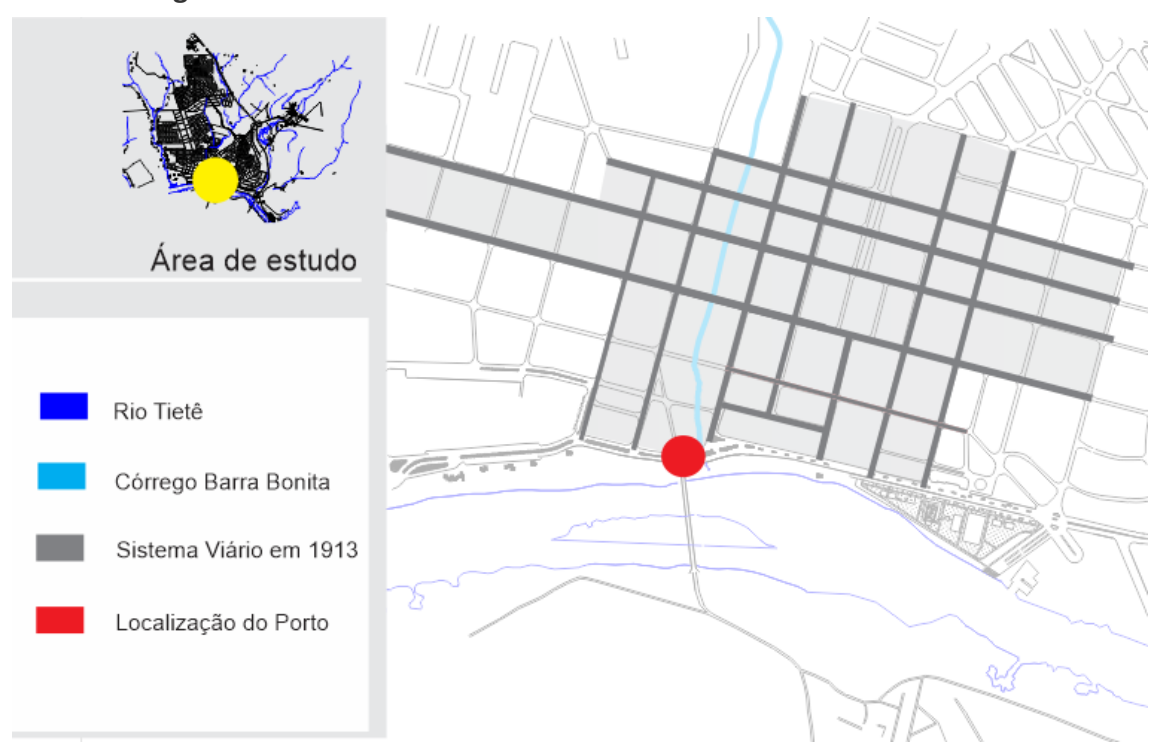

Fonte: Elaborado pela autora.

No Oeste Paulista, a maior parte das cidades se desenvolvia juntamente com as ferrovias. Entretanto no ramal da linha Alta Paulista, as cidades progrediram antes da chegada dos trilhos, de forma que a ferrovia chegava quando os municípios já estavam em pleno desenvolvimento (CONSTANTINO, 2010). É o caso de Barra Bonita, em que a ferrovia terá papel secundário durante toda a sua formação, pois será utilizada principalmente para suprir as necessidades de despachos dos produtos agropecuários durante os períodos de seca do rio. 


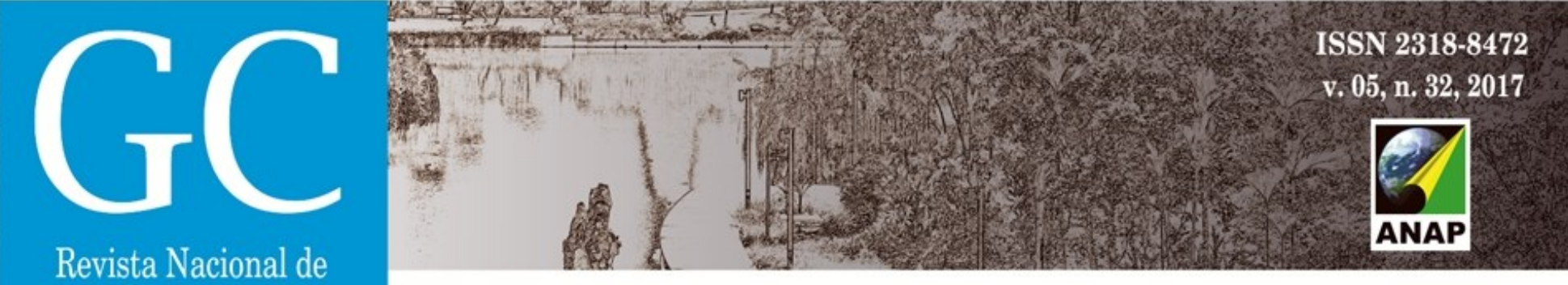

Gerenciamento de Cidades

insumos, diminuição de custos e diversidade de produtos obtidos através da cana. Os primeiros investimentos foram feitos para garantir a produção de álcool etílico anidro, utilizado no setor automobilístico. Segundo o Instituto Nacional de Pesquisas Espaciais, Barra Bonita contava com 63\% (Tabela 1) da área do município ocupada por lavouras de cana no ano de 2004/2005:

Tabela 1: Área de cana safra 2004/2005, cana reforma, área total de cana e porcentagem de cana total em relação à

\begin{tabular}{|c|c|c|c|c|c|}
\hline Município & EDR & Cana Safra & Cana Reforma & Cana Total & $\begin{array}{c}\text { Área do município } \\
\text { ocupada por cana }\end{array}$ \\
\hline Barra Bonita & Jaú & 8.829 & 697 & 9.526 & $63 \%$ \\
\hline
\end{tabular}

Fonte: RUDORFF et al, 2004

A Usina Barreirinho foi originada a partir de investimento particular no setor. Em 1938, o industrial Tage Flohr Svendsen - fundamental para a transição da paisagem da cidade comprou a fazendo Três Barras e, posteriormente a propriedade vizinha Fazenda Barreirinho, criando a Companhia Agrícola e Industrial Barra Bonita (C.A.I.B.B.) em 1946. A Usina da Barra S/A Açúcar e Álcool (UBASA) teve sua origem após a aquisição em 1943 da Fazenda Pau D’Alho -onde já se encontravam duas usinas elétrica e hidráulica - e da Fazenda Aliança pela Usina Costa Pinto. As paisagens se modificaram, deixando de ser um local de plantação de cafezais para a instalação do pólo agroindustrial voltado para a produção de cana, álcool, açúcar. Sob a administração de Orlando Chesini Ometto, pertencente ao grupo sucro-alcooleiro denominado grupo Ometto - é criada em 1949 a UBASA, que posteriormente seria maior produtora do mundo.

À medida que a produção sucroalcooleira aumentava, maior era o movimento de caminhões que transportavam a mercadoria através das estradas. Para tanto, a ponte Campos Salles passou a receber o fluxo, já que era o meio mais rápido de travessia do rio Tietê. Para garantir a preservação da mesma, foi necessário construir uma nova ponte que desviasse o tráfego pesado. A Ponte do Açúcar foi implantada em 1970, interligando Barra Bonita e Igaraçu do 


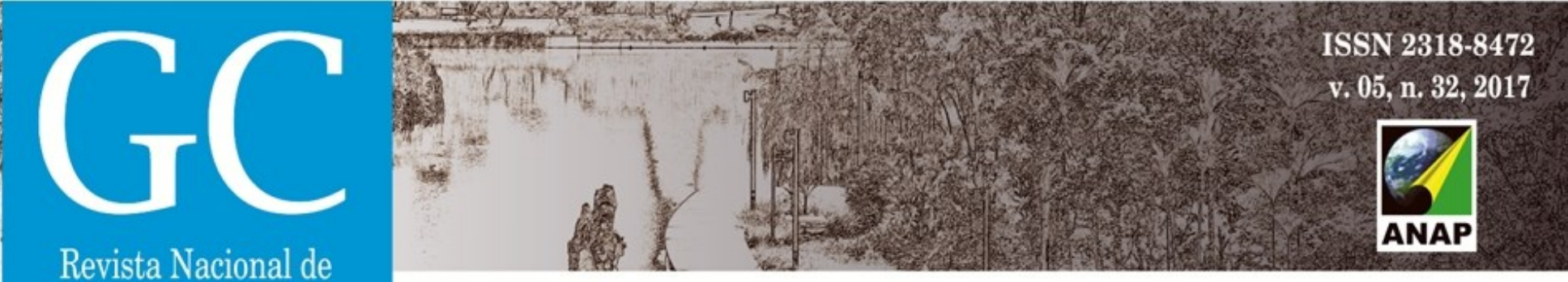

Tietê à rodovia SP-255, Jaú-São Manoel. O então prefeito Dr. Clodoaldo Antonangelo confirma a importância da ponte para a continuidade do desenvolvimento do município:

O fato de estarmos inaugurando uma ponte, junto à lgaraçu do Tietê e Barra Bonita,
cuja base de sua economia, reside no açúcar, ainda hoje lembrávamos de dar uma
denominação que representasse esse potencial econômico regional, que é o orgulho
de São Paulo, porque aqui se radica a maior Usina de Açúcar deste nosso Brasil, em
desenvolvimento. E a idéia foi de sua denominação como PONTE DO AÇÚCAR... Esta
não é uma lembrança que apenas diga respeito aquilo que se produz nesta região. É
um direito que ela tem de marcar com esta obra, o seu potencial básico.
(Jornal da Barra, no 150 de 19 de Setembro 1970)

A última fase reflete o atual momento da cidade reconhecida no setor de turismo, com fortes mudanças urbanas e investimentos no rio Tietê. A Hidrovia Tietê-Paraná e seus Programas de desenvolvimento garantiram a abertura de múltiplas possibilidades de integração econômica, através do desenvolvimento de mercado entre os países da América Latina - Brasil, Paraguai, Uruguai e Argentina, bem como integração regional pela obtenção de um transporte direto que conecta esse grupo. A exploração do Rio Tietê e Paraná refletiu no desenvolvimento das cidades banhadas pelos mesmos, no que tange ao volume de investimentos públicos, privados e de infra-estruturar para a concretização do projeto (BAENINGER et al, 2002). O eixo emergente, localizado no Médio Tietê Superior, abrange, entre outros, a Região Administrativa de Bauru,sendo esta beneficiada pela construção da usina hidrelétrica de Barra Bonita. Visando o desenvolvimento das cidades paulistas banhadas pelo rio Tietê ${ }^{1}$, o Projeto Calha orienta a disposição dos investimentos de acordo com a capacidade e necessidade de cada município, resultando na interiorização da indústria, desenvolvimento agropecuário, turismo e preservação do patrimônio ambiental (CITP/SCTDE, 1994). Barra Bonita passou a ocupar posição de destaque entre as cidades da região do centro-oeste paulista graças ao grande investimento financeiro por parte do governo do Estado e do investimento do Município, tanto em obras públicas como no setor de turismo. Isso abriu novas portas e aumentou as perspectivas para o progresso da cidade. A categorização da cidade de Barra Bonita como "turismo permanente" alavancou o desenvolvimento do setor no município, trazendo também beneficio para outras cidades da Região, com aumento no número de visitantes. Por razão disto, o Poder Público passou a criar infraestrutura para poder melhor atender às necessidades desse setor cada vez mais importante para a cidade. Isso fez com que o Poder Público investisse em medidas que trouxeram beneficio para o comércio mais atuante na hotelaria e setor alimentício, como restaurantes, lanchonetes e bares.

A partir de 2006, a cidade passa adotar medidas para aproveitar o potencial turístico do rio Tietê. Segundo o plano diretor de Barra Bonita, a partir de 2006 foi proposta a aplicação de

\footnotetext{
${ }^{1}$ Os 86 municípios estão localizados ao longo do rio, iniciando pela cidade de Itu até Ilha Solteira .
} 


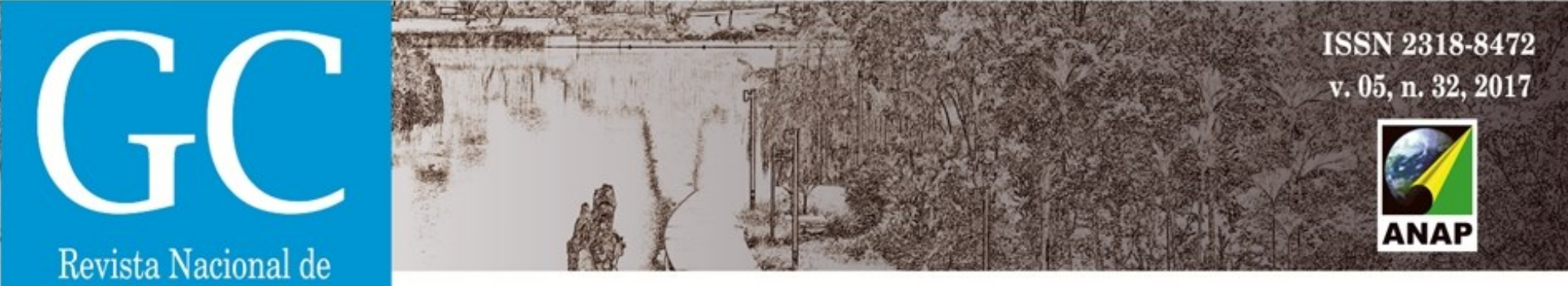

Gerenciamento de Cidades

instrumentos urbanísticos para alavancar o turismo local e regional. Algumas medidas diretamente relacionadas ao rio foram o aprimoramento do turismo náutico e promoção da pesca esportiva ${ }^{2}$. Além disso, a partir da política ambiental da cidade, o rio Tietê deveria passar por recuperação de suas águas, despoluindo e recuperando as matas ciliares. ${ }^{3}$

\section{CONCLUSÃO}

O estudo da cidade de Barra Bonita permitiu a análise da evolução da forma urbana através dos anos, tão intimamente ligada ao rio Tietê. Através da análise, Barra Bonita pôde ser dividida em fases históricas, associadas às diferentes formas de "ver o rio" e os diferentes usos. O Rio representa a coluna vertebral da cidade de Barra Bonita, onde todos os aspectos se sustentam no rio. Barra Bonita apresenta atividades econômicas, desenho urbano e até mesmo o comportamento social pautados no desenho geológico do rio.

\section{REFERÊNCIAS BIBLIOGRÁFICAS}

BESSE, J. M. Las cinco puertas del paisaje: ensayo de una cartografía de las problemáticas paisajeras contemporáneas. In: MADERUELO, J. (org.). Paisaje y pensamiento. Madrid: Abada, 2006. p. 145-171.

LANGENBUCH, J. R. A estruturação da Grande São Paulo. Rio de Janeiro: IBGE, 1971

CORRÊA, D.S.; ALVIM, Z.M.F. A água no olhar da história. São Paulo: Secretaria Estadual do Meio Ambiente, 2000.

SAFFI, L., BOMBONATI, I. C., BOLLA, R. A., STANGHERLIN, C."100 anos de história Barra Bonita - De Salles

Leme e Pompeu (1883) a WadyMucare (1983)",1999. Prefeitura Municipal de Barra Bonita. Disponível em:

<https://barrabonita.sp.gov.br/?page=livro-100-anos-de-historia> Acesso em: 10 de mar. de 2016.

SILVA, H. M. M. Café, Imigração e Urbanização no Interior Paulista. Fatos e Versões. V.5, 2013

CONSTANTINO, N. R. T. A estrutura agrária na formação do tecido urbano das cidades do Oeste Paulista. In: SALGADO, I.; BERTONI, A. Da construção do território ao planejamento das cidades: competências técnicas e saberes profissionais na Europa e nas Américas (1850-1930). São Carlos: Rima/FAPESP, 2010. p.35-49.

BRANCO, Z. M. Catulo Branco: um pioneiro In MEMÓRIA E ENERGIA. São Paulo: Fundação Patrimônio Histórico da Energia de São Paulo, n. 27. 2000, 96 p.

\footnotetext{
${ }^{2}$ Art. 45 - No processo de expansão do turismo, o Poder Executivo adotará as seguintes diretrizes: VIII - promoção da pesca esportiva no Rio Tietê, respeitando-se a legislação pertinente; XII - ampliação e aprimoramento do turismo náutico, aproveitando-se das potencialidades do Rio Tietê. CAPÍTULO IV DO DESENVOLVIMENTO DO TURISMO SUSTENTÁVEL.

${ }^{3}$ Art. 51 - A política ambiental de Barra Bonita deverá obedecer às seguintes diretrizes: I - Incentivar a recuperação da qualidade da água do Rio Tietê e recuperação dos demais cursos d'água municipais, despoluindo-os e recuperando suas matas ciliares;
} 


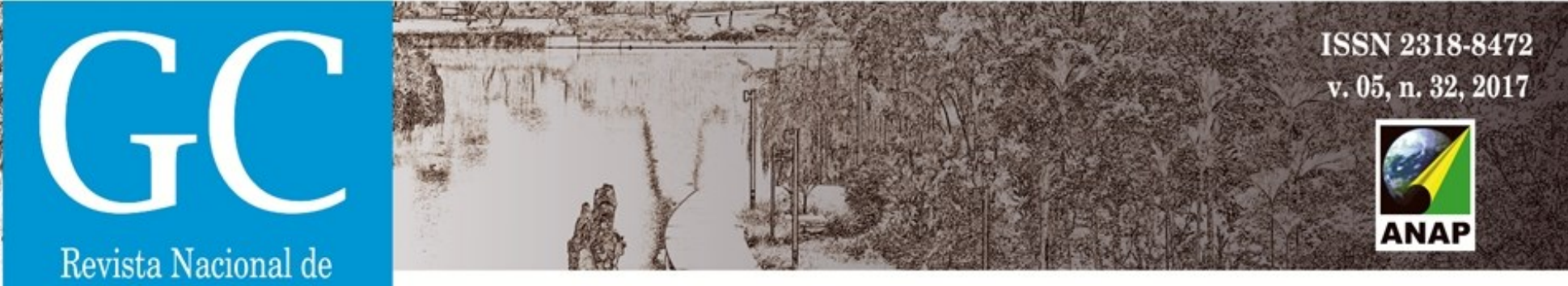

Gerenciamento de Cidades

National Journal of Cities Management

BAENINGER, R.; LEONELLI, G.; BOLLIGER, C. Municípios da Hidrovia Tietê-Paraná: regionalização e dinâmica sócioespacial. In: XIII ENCONTRO DA ASSOCIAÇÃO BRASILEIRA DE ESTUDOS POPULACIONAIS, Ouro Preto, Minas Gerais, Brasil, 2002. 